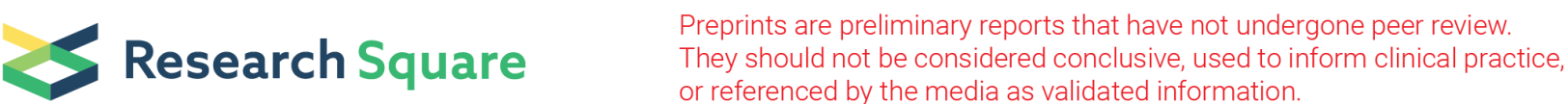

\section{Is precariousness the blind spot of prevention and treatment of the use of psychoactive substances?}

Philippe Chossegros ( $\nabla$ philippe.chossegros@chu-lyon.fr)

Centre Hospitalier Universitaire de Lyon https://orcid.org/0000-0002-0098-8843

Fiorant Di Nino

Association Ithaque

Research

Keywords: drug use, Respondent Driven sampling, precariousness, housing, health coverage, income, social networks

Posted Date: April 20th, 2020

DOI: https://doi.org/10.21203/rs.3.rs-22462/v1

License: () (7) This work is licensed under a Creative Commons Attribution 4.0 International License. Read Full License 


\section{Abstract}

Background and aims: Prevalence of the use of psychoactive substances is high in precarious populations. Yet the influence of precariousness on the trajectory of drug users (DUs) has rarely been studied. For the first time, we conducted such a study with a representative group of DUs.

Methods: We combined a recruitment through a respondent driven sampling (RDS) with a 250 items questionnaire. The answers of our sample of 327 UDs were studied according to a precariousness score (PS).

Results: The prevalence of precariousness ranged from low PS $48.9 \%$, average PS $30.9 \%$ to high PS $20.2 \%$. Access to health services at the time of our survey concerned $61.8 \%$ of DUs. Its prevalence was lower among DUs with the highest precariousness score (Low PS $72.5 \%$, Average PS $61.4 \%$, High PS $36.4 \%)$ with an Odds ratio of 5.01 ( $\mathrm{CI} 95 \%$ 2.52-9.97; $\mathrm{p}<0.0001)$ between low and high PS for a continuous follow-up. A higher dropout rate was also observed among the highest PS $(\mathrm{p}<0.0001)$.

Despite differences in their socio-economic characteristics, DUs represented a homogeneous community with respect to their use of drugs. The more precarious DUs were younger, had an earlier age of initiation of injection, of experimentation of cannabis, alcohol, heroin as well as diverted opioid substitution treatments (OST). They had a more frequent and durable use of alcohol. Precariousness was also associated with lower educational levels, less contacts with one's parents, less search for information on the Internet for drugs and GPs for health and more housing and social rights as plans for the future.

Conclusion: In France, despite the fact that specialized care is free of charge, the lower access to for the most precarious DUs and their higher drop-out rates suggest that it is not adapted to their demand, which is more oriented towards socio-economic problems than towards drug use or harm reduction. This observation is all the more important as it concerns the youngest users. Our data suggest that precariousness influences the course of drug addiction from its onset. Lack of consideration of this population limits the ability to develop effective health policies.

\section{Introduction}

Precariousness has been defined as "the absence of one or more of the security features that allow people to assume their basic responsibilities and enjoy their fundamental rights. The resulting insecurity may be more or less widespread and have more or less serious and definitive consequences. It most often leads to extreme poverty when it affects several areas of life, tends to extend over time and becomes persistent, seriously compromises the chances of regaining one's rights and reassuming one's responsibilities on one's own in the foreseeable future" (1). Its relationship between drug use and precariousness is recognized and has been usually assessed through the prevalence of DUs among populations selected for homelessness, low income or low social security affiliation (1-9). These problems are often considered as being the consequence of using psychoactive substances. Less consideration has been given to their influence on the initiation of drug use, on its course and to the access to health services. Targeting at risk DU, many surveys are unable to give a global understanding of its influence on the initiation of drug use, on its course and to the access to health services (11-15). Like the majority of the studies of DUs, as is the case of surveys of the prevalence of hepatitis $(16,17)$, the bulk of French publications $(18,19)$ concern services for DUs, ignore GP's who prescribe $2 / 3$ of the opioid substitution treatments (20), and ignore UDs outside these dedicated health services.

France remains a welfare state where social protection is important and care is free which applies to drug addiction for which services (SDUs) were set up in the early 1970s. From 1996, to treat heroin addiction, this offer was completed, in these SDUs, by the creation of methadone units and by the offer made to every GP of prescribing high dosage buprenorphine (21).

After the failure of a first snowball survey involving all Strasbourg's SDUs in 2011, we decided to switch to a RDS since it is the most widely used method for studying hidden populations (22). It serves, among others, the US CDC to assess the prevalence of HIV infections (23). The originality of our approach comes from its association with a questionnaire of more than 250 items, created by caregivers and DUs, covering every area considered relevant to better understand DUs' trajectories.

After hepatitis C (24), we present here the study of precariousness. This is the first quantitative study of this type involving a representative population of DUs regardless of an history of injection or of their access to the health services and aggregating three variables in a score of precariousness, created by the Observatoire Français des drogues et des toxicomanies to reflect the extremely precarious situation of many DUs (25). This recruitment allows us to position drug use with care supply according to this feature.

\section{Methods}

\section{Study design}

Our study was conducted in the greater Strasbourg area (15-64 years: 473375 people). RDS was chosen to recruit a representative sample of DUs. The condition of their eligibility followed the European Monitoring Centre for Drugs and Drug Addiction definition of problematic drug use: injecting drug use or long duration /regular use of opioids, cocaine and/or amphetamines. (26).

We used a precariousness score (PS) created by the French Observatoire des Drogues et des Toxicomanies: (24). Its three items (Health coverage : 0: affiliated to a Social Security scheme with complementary coverage; 1 : affiliated to a Social Security scheme without complementary coverage (including people with universal medical coverage or free health care for people on low incomes); 2 no Social Security scheme (with or without state medical assistance). Housing: 0: long-term (independent or with friends/family); 1 : in an institution or temporarily with friends/family; 2 : homeless or living in a squat. Origin of income : 0: employment income and/or unemployment benefits; 1 : social welfare or funds from third parties; 2 : other funds (illegal or unofficial) and no income) 
We started with 3 "seeds" randomly recruited among DUs attending the same SDU. They were asked the number of DUs they had met in the previous 14 days (network size) and were given 3 coupons to recruit 3 respondents among their own social network who were due to show up less than 14 days later. Each wave of respondents, following the same rules, recruited the next wave until the final sample size was achieved. Our budget allowed financing the recruitment of 300 DUs representing a sample of $6 \%$ of the total population of DUs of the greater Strasbourg area (27).

The completion by each respondent of a 250 items auto-questionnaire was followed by a cross examination of their answers in a private space by the same professional interviewer to assess their quality and completeness. The monetary recruitment incentive was $30 €$ for the completion of the interviewer-

administered questionnaire and $20 €$ for each recruited DU. This amount, was considered to be a fair salary, recognizing an actual work, by the DUs who had validated the questionnaire. Since giving money unconditionally regarding its use to homeless and other low income individuals, among which DUs, has constantly been shown to improve their empowerment, this approach was considered ethical $(28,29)$. The conduct of the study was in line with the ethical checklist (respect, beneficence, justice, and safeguards) provided by Semaan and al. (30).

Patients provided informed consent to participate to the study and to publish its results. This study was approved by the French CNIL (Commission Nationale de l'Informatique et des Libertés). Data was anonymous and used in accordance with the European GDPR.

\section{Statistical analysis}

RDS allows statistical adjustments for differential network sizes to produce estimates representative of the sampled population's network. RDS data weighting was used to compare the observed distribution of HCV screening between the observed and the weighted population as well as their homophily for sex, age, using RDSAT version 7.1.46:

(http://www.respondentdrivensampling.org/reports/RDSAT_7.1-Manual_2012-11-25.pdf; http://www.respondentdrivensampling.org/download/RDSATv7.1.46/RDSAT_windows-x64_7_1_46_noJRE.exe). We followed the "STROBE-RDS" reporting recommendation (21).

The items constituting the PS were compared to all the other variables. For ordinal or categorical variables chi-square and odds) ratio or Kendall tau-b were calculated. T-test or one-way ANOVA were performed for scale variables. Since multiple comparisons were performed, statistical significance was considered at an alpha of 0.01 to prevent the occurrence of too many statistically but not clinically relevant associations. To measure the association between dependent and independent variables, the significant variables were entered into binary logistic regression multivariate models and automatically chosen by forward stepwise selection procedure (2-sides, $\mathrm{p}<0.05)$. Odds ratios $(\mathrm{OR})$ and $95 \%$ confidence intervals $(\mathrm{Cl})$ were calculated from $\beta$ coefficients and their standard errors. The Hosmer-Lemshow test was used to determine the goodness of fit of the models. The data were analyzed using IBM SPSS version 19.

\section{Results}

\section{Respondent driven sampling and characteristics of drug users}

We recruited 327 DUs in 2 months (February-March 2015). All participants met the conditions of the survey. None of the 3 chains were interrupted before it reached the planned number of inclusions, with a maximum number of 6 waves. The average number of DUs encountered during the 15 days preceding interviews was 13.6 (95\% Cl 11.6-15.5).

DUs characteristics are presented in table 1 (observed, weighted and homophily data). Since there were no significant differences between the observed and weighted data, the subsequent statistics were conducted with the observed data.

The highest prevalence of women under $20(51.7 \%(95 \% \mathrm{Cl} 34.4-68.6))$ disappeared gradually with age (overall average: $25.7 \%(95 \% \mathrm{Cl} 21.3-30.6)$ was independent from the PS.

Precariousness is presented in table 2 and its relationship with age in Table 3. It was strongly related to the educational level $(p<0.0001)$ : Before bachelor degree (Low PS 58.8\% (95\%Cl 51-66.1), Average PS 79.2 \% (95\%Cl 70.3-86)), High PS 92.4 \% (95\% Cl 83.5-96.7)), University degree +/- Master (Low PS 21.3\% (95\% Cl 21.3-28.2)), Average PS $5.9 \%$ (95\% Cl 2.8-12.4), High PS $0 \%)$. There was no difference in PS for history of incarceration (49.5\%). If moonlighting was related to precariousness (Low PS: $5.6 \%(95 \% \mathrm{Cl} 3-10.3)$, Average PS: $19.8 \%$, (95\% Cl 13.2-28.6) High PS: $42.4 \%(95 \% \mathrm{Cl} 31.2-54.4)$; p<0.0001), it was not the case for illegal incomes $(25.7 \%(95 \% \mathrm{Cl} 21.3-30.7))$. Precariousness was not related to sex.

\section{Drug use}

Drugs used over the course of life and within the last 30 days are presented in Table 4 . Addiction (90.5\%) was not related to precariousness.

A history of injection was reported by $62.2 \%$ (95\% Cl 56.7-67.2) with $34.9 \%(95 \% \mathrm{Cl} 29.9-40.2)$ of needle-sharing and $29.1 \%(95 \% \mathrm{Cl} 24.4-34.2)$ of syringes and needle sharing related to craving. They were unrelated to PS. In contrast, the age of onset of injections was younger (Low PS: 22.15 years (95\% Cl 21.1-23.2)/ Average PS: 20.1 years (95\% Cl 18.9-21.25) / High PS: 19.35 years (95\% Cl 17.7-21); Kendall's tau-B: $\mathrm{p}<0.0001)$.

\section{Access to dedicated health services}

DUs formed 3 groups according to their use of health services: continuous, dropout and never used The prevalence of continuous attendance increased with age from 10.3\% (95\% Cl 3.6-26.4) below 20 years to 75,7\% over 30 years (95\% Cl 63.4-81.1) while that of never use follows a reverse trend from 75.9\% (95\% $\mathrm{Cl}$ $57.9-87.8)$ to $0 \%$ over 50 years. The dropout rate remains stable $(13.8 \%, 95 \% \mathrm{Cl} 10.45-17.9)$. The relationship between precariousness and use of health 
services is described in Figure 1. The odds ratio of a continuous use of HCS versus never attending them was 5.01 (CI95\% 2.52-9.97) between DUs with the highest and the lowest level of precariousness and 2.13 (1.04-4.35) between DUs with an average level of precariousness and those with the highest level $(p<0.0001)$. Drop out was also more frequent between DUs with the highest and the lowest level of precariousness $(3.98 ; \mathrm{Cl} 95 \% 1.73-9.15)$ as well as between average and high level of precariousness (2.58 CI95\% 1.07-6.22).

Before the age of 20, precariousness affected $45.5 \%(95 \% \mathrm{Cl} 26.9-65.3)$ of the DUs that had never had access to health services. The first contact with care for drug use was earlier in the most precarious (Low PS 26.3, Average PS 23.2, High PS 23.2; $p=0.005$ ). High PS was more prevalent in SDUs (17.3 \%) than in GPs' offices $(8.1 \%, p<0.0001)$. The number of drugs used in the past 30 days was not related to PS or to the history of care.

Among the 160 Low PS, $34(21.25 \%(95 \% \mathrm{Cl} 15.6-28.7)$ where still using drugs and did not consult health services at the time of the survey. They did not moonlight and had the same proportion of illegal activities as other DUs. They were different because of a better education (higher than bachelor: $31.1 \%$ / $21.9 \%, p<0.0001)$ and a lower level of imprisonment $(3.9 \% / 52.9 \%, p<0.0001)$.

The prescription of an OST in the course of life was inversely related to PS (Low PS: $70 \%(95 \% \mathrm{Cl} 62.5-76.6))$, Average PS: $60.4 \%$, (95\%Cl 50.7-63.4) High PS: $31.8 \%(95 \% \mathrm{Cl} 21.9-43.8) ; \mathrm{p}<0.0001)$. On the other hand, there was no difference related to PS for the age of onset of the OST prescription.

The absence of relationship between HCV screening $(82 \%(95 \% \mathrm{Cl} 77.4-85.8)$ and PS may be explained by screening in prison. Among those who had never been to prison its prevalence was $55.2 \%(95 \% \mathrm{Cl} 37.6-72)$ whereas it reached $100 \%$ for those who had been imprisoned. Among DUs screened for HCV, the prevalence of infections (22.8\%) was independent of the PS. HIV prevalence was low $(1.7 \%, 95 \% \mathrm{Cl} 0.75-4.03)$.

Sexual preferences were not influenced by PS, Condom use was related to the number of sexual partners $(p<0.0001)$ which was also higher among DUs with a HPS (Always use of condoms: LPS $20.9 \%$, APS $27.9 \%$, HPS $40 \%$; $p<0.0001$ ).

\section{Sources of information}

The different sources of information are presented in Table 5. Apart from GPs for health, friends remained the primary source of information. The use of social networks, predominant among the youngest was not influenced by PS, unlike the use of television watched by older DUs. The association between Internet access and precariousness was explained by its association with education level (high) and age (youth).

\section{Fears and plans for the future}

Fears were not influenced by precariousness. Finding housing (Low PS 15.6\% (95\% Cl 10.8-22.1) /Average PS 50.5\% (95\% Cl 40.9-60) / High PS 60.6\% (95\% Cl 48.6-71.5); $\mathrm{p}<0.0001)$, change of housing (Low PS 28.7\% (95\% Cl 22.3-36.2)/Average PS 25.7\% (95\% Cl 18.2-22.1)/ $\mathrm{High} \mathrm{PS} 9.1 \%(95 \% \mathrm{Cl} 4.2-18.4)$; $\mathrm{p}=0.006)$, recovering social rights (Low PS 7.5\% (95\% Cl 4.3-12.7)/Average PS 15.8\% (95\% Cl 10-24.2) /High PS 36.4\% (95\% Cl 25.8-48.8); p<0.001) and changing of work (Low PS 11.9\% (95\% Cl 7.7-17.8, Average PS 4\% (95\% Cl 1.6-9.7), High PS $0 \%$; $p=0.002$ ) were the only plans for the future influenced by precariousness.

\section{Contacts}

Precariousness differentiated DUs by the number of contacts in the last 30 days with their parents (median Low PS 2, Average PS 1, High PS 0, Mann Whitney $p<0.001$ ), with the number of dealers encountered (median Low PS 1, Average PS 2, High PS 2, Mann Whitney $p=0.001$ ). The presence of a contact or the number of contacts with a dealer were not influenced by the attendance to care. The number of friends and of DUs was not related to precariousness.

\section{Multivariate analysis}

A step-by-step forward binary logistic analysis was carried out to specify the elements that differentiated the DUs with a Low PS from those with a HPS. All variables significantly associated with precariousness were entered. These results are shown in Table 6.

\section{Discussion}

For the first time, using a specific score created by the organization in charge of studying drug addiction in France to accommodate the particularly high precariousness of DUs (25) we have been able to study its significance, and especially its influence on the course of drug consumption and on access to care for a representative sample of DUs in a large French agglomeration (greater Strasbourg area, 15-64 years: 473375 people). In less than 3 months, RDS allowed to recruit 327 DUs representing about $6 \%$ of the population of the problematic DUs (33). Two-third of these DUs attended services for their addiction and among them, two-third were treated by GPs.

Despite the absence of data on the prevalence of DUs' access to health services, we were able to assess the representativeness of our recruitment through their agreement with the known data such as the high heroin consumption specific to DUs in eastern France (31), the proportion of DUs receiving OST prescribed by GPs (20) as well as age and sex distribution, injection prevalence or precariousness for DUs attending specialized services for DUs (18,19). Thus, limited to the population included in the French surveys of specialized services for DUs and the hepatitis C Coquelicot survey of 2011 (17), we would have ignored $77.1 \%$ of our sample and $80.3 \%$ of the most precarious DUs.

We observed a community of DUs very diverse socio-economically, but homogeneous for the use of drugs. If, each characteristic was associated with a significant positive homophily, its level remained moderate, testifying to the absence of real boundaries between DUs' categories. This was true for precariousness that was, however, significantly associated to a different course of drug addiction. 
Drug use followed the same pattern for all, in accordance with previous studies (33-35): It began in the early teens with cannabis and alcohol, followed by heroin and cocaine around 20. The other drugs appeared a little later with ketamine and diverted OSTs later. Poly-experimentation was the rule, reflecting the wide availability of products. Three fourth had a history of OST prescription. Moonlighting and illegal work were common. The lower prevalence of Illegal income than that reported by Debeck et al (35) may be related to difference in recruitment and in the use of welfare. Precariousness had and influence on this pattern. It was associated, as in low threshold services (18), with an earlier age of initiation of cannabis, alcohol, heroin use, of onset of injections and of OST misuse, with a more frequent alcohol use over the course of life as well as over the previous 30 days. The other information collected (lack of contact with the parents, school failure) placed this escalation as an early adaptation to an existential situation that drug use helped to support without resolving it, leading to school drop-out, higher unemployment, illegal work and, above all, moonlighting and homelessness, emphasizing the interest of very early prevention actions. This hypothesis is confirmed by the higher PS of DUs attending SDUs than GPs' offices, who are less able to provide social assistance and may ask to put the money of the consultation forward. Their higher homophily, since they had less contacts inside health services, can be linked only to encounters with less precarious DUs occurring around the use of drugs, confirming the existence of a drug related community. Housing, financial and educational deficits could contribute to the lower use of television and of the internet as sources of information. The relationship between precariousness and care by GPs explains why the most precarious had less recourse to them as a source of information on health. We have explained the low level of risk taken by the most precarious by group mimicry than by rational knowledge (24). This situation explains that finding a housing, with the desire to recover one's social rights-were the only plans for the future associated with high precariousness. If we confirm the interest of peer support emphasized by the predominant use of friends as sources of information, social networks, even if their use was lower than in the general population, should be also targeted since it was not influenced by precariousness.

The interpretation of later evolution is more uncertain because of the cross sectional design of our approach. The significant decrease in our sample size with age, more frequent among the most precarious and those who remained outside of care, suggests several interpretations that are not mutually exclusive:

- This trend could be related to a high mortality well documented among DUs (36-41) that can occur early in the course of drug use (40). Its impact will have been particularly important among the oldest DU who started their injections in the 1980s and paid a high toll to HIV before the introduction of HAART (42) and, until 1996, to overdoses before the liberalization of OST prescription as evidenced by the first cohort study of the OFDT conducted from 1992 to 2002, which was already too late to measure the real impact of the HIV epidemic (36). A higher death-rate related to precariousness could participate in this decline $(43,44)$.

- Drug discontinuation, with or without medical support, is well documented by population surveys for tobacco, alcohol, and to a lesser extent, other drugs (45-48). In France, In general population surveys, the use of illicit drugs other than cannabis disappears after age 45, and, for cannabis, and, declines sharply after age 29 and disappears after age 60 (49). In our sample, the number of currently used drugs, lower than that of their total number consumed during life, reflects this reality. The female predominance observed among younger DUs in low threshold services (18) was found in our sample. Its disappearance with age implies that it does not translate a simple disaffection of care, but may be either related to a discontinuation of drug use in which pregnancies can play a role, or, less likely, to a recent masculinization of the use, or both. The absence of a relationship between the projects to stop drug use and duration of consumption, the number drugs consumed or the access to care explains that this phenomenon can occur at any time of drug use.

- The care provided in the SDUs may have enabled some users to get out of precariousness, but the low access to health services and the high dropout makes this evolution, at best, marginal.

- Last and not least, it could be related to a switch toward other drugs. In the 1980s, DUs unable to finance a sustainable consumption of heroin that had led them to an early initiation of injections (35) turned to an already present alcohol consumption, sometimes after an early and discontinued contact with a care unable to give them the answers they were waiting for. It was the rule in France before the introduction of a very wide OST offer in 1996 . The recent high alcohol consumption among the most precarious and the lowest number of contacts with drug dealers are consistent with this hypothesis. Today, with the diversification of products and their distribution, we are witnessing a change in consumption (31). This trend has been observed in many French regions and worldwide $(50,51)$. Young people living on the street use prescription drugs rather than heroin and cocaine at a time when,

paradoxically, illicit drugs are being considered to treat psychiatric pathologies, reawakening the 1980s theory of drug use as self-medication. (52-56). They are easily accessible and inexpensive at the street level. The switch from heroin and cocaine to other psychotropic drugs, excluding these DUs from our study, would explain their disappearance.

From the PS, we can deduce three populations according to their use of SDUs, division which was subjectively obvious for the investigator who received the DUs (invisible, concealed and motionless):

- For $10.4 \%$ of the DUs (invisible) in our survey a better social integration was associated with a lack of care seeking, reflecting a consumption compatible with a normal social life reflected by the lower prevalence of unofficial work and incarceration history. The absence of university degrees and masters among the most precarious DUs reinforces the hypothesis of a deleterious interaction between precariousness and drug use that began as soon as drugs were experimented with.

- At the other extreme, several interpretations may explain that two-thirds of the DUs in great precariousness (concealed) remained outside the care at the time of our survey and that they disappeared with age, with the odds ratio by far the highest in our study. An offer that does not meet the expectations of precarious DUs would explain the importance of the link of precariousness with their low prevalence among consultants at the time of our survey, an early contact and a frequent abandonment when they had previously approached them, occurrence even greater among the youngest. This hypothesis is confirmed by the higher PS of DUs attending SDUs than GPs' offices, who are less able to provide social assistance and may ask to put the money of the consultation forward, by housing as their first demand and by the absence of influence of OST prescription, the number of drugs consumed or the contacts with drug dealers during the month preceding our survey. Our conclusion is in agreement with the finding of Luongo et al and of Philips et al of the need for tailoring theses services to this population $(12,13)$ and with our observation that hepatitis screening was not a reason for consulting DUs (24). 
- At last, DUs who found their balance in the current offer of care (motionless) where the OSTs "evened out" drug use rather than led to its discontinuation. Their intermediate precariousness allowed them to adapt to the constraints of social life with the help of SDUs' teams as reflected by a significantly higher prevalence of Social Integration Income (Continuous $59.4 \%$, Dropout $33.3 \%$, Never $21.3 \%$; p 0.0001 ). The high level of viral screening and access to hepatitis treatments we observe (24) is consistent with the harm reduction role of the dedicated services by Kennedy et al (57).

\section{Conclusion}

Our survey, studying, for the first time, the influence of precariousness among all the at-risk DUs of a French urban area, provides information essential to understand the course of drug use and the access to dedicated services. Precariousness does not appear to be first a consequences of drug use, but rather, on the contrary, the consequence of profound emotional and social dysfunctions that predate drug use, leading to its experimentation at the same time as the social situation deteriorates. Thus, no simple solution can be found in the pharmacological treatment of these addicts whereas what is sought concerns the healing of the psychological and the social harm. Our finding may be surprising since access to the dedicated services is easy and free in France, however the particularly high rate of unemployment and the deficit of access to social housing among the young may explain this discrepancy $(58,59)$. We believe, agreeing with Kiluk et al. (60) that sustained abstinence cannot be accepted as the only end-point of the treatment of DUs. For most users, and even more so for the most precarious, providing solution to educational, housing, income, work and social security problems should be considered at least at the same time as providing psychological and substance use disorders treatments. Once found effective solutions, depending of the local situation, we believe that, as for the detection and the treatment of viral infection (23), conditional cash transfer could be an effective approach to implement them if the proposed offer meets expectations. These conclusions need to be validated by other similar studies conducted in different environments and by cohort whose selection would follow the same design. If our conclusions were confirmed, the evaluation of healthcare policies related to drug use, including harm reduction measures, should be re-evaluated.

\section{Declarations}

\section{Ethics approval and consent to participate and to publication}

This study was approved by the French CNIL (Commission Nationale de l'Informatique et des Libertés). The database was anonymized.

\section{Consent for publication}

Apart from the 3 initial seeds to whom the study was presented by FD, all the other respondents were recruited by peers who explained the setting of the study. They decided voluntarily to be included in the study even before getting in touch with FD. All recruited DUs gave an informed consent to participate and to publication.

\section{Funding}

This research was funded by the "Fonds de dotation Gilead Sciences". The grand was awarded by a committee independent of Gilead Sciences. Role of the funding source: GILEAD had no role in study design, in the collection, analysis or interpretation of the data, nor in the writing or submission of the manuscript.

\section{Availability of data and material}

The datasets used and/or analyzed during the current study are available from the corresponding author on reasonable request.

\section{Competing interests}

The authors declare that they have no competing interests (FDs' salary was paid y the grant)

\section{Author's contribution}

P Chossegros and F Di Nino conceived the study and supervised all aspects of its conduct. PC conducted the statistical analysis. PC and F Di Nino wrote the first and subsequent manuscript drafts.

\section{Author's information}

P Chossegros was involved in the treatment of hepatitis B, C and D since the end of the seventies and of HIV infections since the beginning of the AIDS epidemic. He was the cofounder of a healthcare network for DUs in Lyon in 1993 and participated in the creation of the National Healthcare Network en 1997 of which he has been President until 2003.

\section{References}

1 Wresinski J. Grande pauvreté et précarité économique et sociale, Journal Officiel, 1987, p 6 https://www.google.com/url? sa=t\&rct=j\&q=\&esrc=s\&source=web\&cd=2\&ved=2ahUKEwjf2YfU9_DiAhVWBGMBHUrfCXkQFjABegQIAhAC\&url=http\%3A\%2F\%2Fwww.lecese.fr\%2Fsites\%2Fde WRESINSKI.pdf\&usg=AOvVaw0TvHMrMtuyQBnP8gKjfVOj (Accessed march 2020)

2 Riley ED, Shumway M, Knight KR, Guzman D, Cohen J, Weiser SD.. Risk factors for stimulant use among homeless and unstably housed adult women. Drug Alcohol Depend 2015;153:173-9. 
3 Charitonidi E1, Studer J, Gaume J, Gmel G, Daeppen JB, Bertholet N. Socioeconomic status and substance use among Swiss young men: a populationbased cross-sectional study. BMC Public Health 2016;16:333.

4 Friedman SR, Tempalski B, Brady JE, West BS, Pouget ER, Williams LD, Des Jarlais DC, Cooper HL. Income inequality, drug-related arrests, and the health of people who inject drugs: Reflections on seventeen years of research. Int J Drug Policy 2016;32:11-6.

5 Wang N1, Xie X2 The impact of race, income, drug abuse and dependence on health insurance coverage among US adults. Eur J Health Econ 2017; 18:537546 .

6 Smith OM, Chant C, Burns KEA, Kaur M, Ashraf S, DosSantos CC, Hwang SW, Friedrich JO. Characteristics, clinical course, and outcomes of homeless and non-homeless patients admitted to ICU: A retrospective cohort study. PLoS One 2017;12:e0179207.-

7 Doran KM, Rahai N, McCormack RP, Milian J, Shelley D, Rotrosen J, Gelberg L. Substance use and homelessness among emergency department patients. Drug Alcohol Depend 2018;188:328-333.

8 Santa Maria D, Padhye N, Yang Y, Gallardo K, Santos GM, Jung J, Businelle M. Drug use patterns and predictors among homeless youth: Results of an ecological momentary assessment. Am J Drug Alcohol Abuse 2018;44:551-560.

9 Henkel D. Unemployment and substance use: a review of the literature (1990-2010) Curr Drug Abuse Rev 2011;4(1):4-27.

10 Viner RM, Ozer EM, Denny S, Marmot M, Resnick M, Fatusi A, Currie C. Adolescence and the social determinants of health. Lancet 2012;379:1641-52.

11 Richardson L, DeBeck K, Feng, C, Kerr T, Evan Wooda E. Employment and risk of injection drug use initiation among street involved youth in Canadian setting. Prev Med 2014; 66: 56-59.

12 Luongo NM1, Dong H, Kerr TH, Milloy MS, Hayashi K, Richardson LA. Income generation and attitudes towards addiction treatment among people who use illicit drugs in a Canadian setting. Addict Behav 2017;64:159-164.

13 Phillips M, Richardson L, Wood E, Nguyen P, Kerr T, DeBeck K. High-Intensity Drug Use and Health Service Access Among Street-Involved Youth in a Canadian Setting. Subst Use Misuse 2015;50:1805-13.

14 Long C, DeBeck K, Feng C, Montaner J, Wood E, Kerr T. Income level and drug related harm among people who use injection drugs in a Canadian setting. Int J Drug Policy 2014;25:458-64.

15 Booth BM1, Wright PB, Ounpraseuth ST, Stewart KE. Trajectory of substance use after an HIV risk reduction intervention. Am J Drug Alcohol Abuse 2015;41:345-52.

16 Jauffret-Roustide M1, Le Strat Y, Couturier E, Thierry D, Rondy M, Quaglia M, Razafandratsima N, Emmanuelli J, Guibert G, Barin F, Desenclos JC. A national cross-sectional study among drug-users in France: epidemiology of HCV and highlight on practical and statistical aspects of the design. BMC Infect Dis 2009;9:113

17 Jauffret-Roustide M., Pillonel J., Weill-Barillet L., Léon L., Le Strat Y., Brunet S., et al., Estimation de la séroprévalence du VIH et de I'hépatite C chez les usagers de drogues en France - Premiers résultats de l'enquête ANRS-Coquelicot 2011. BEH $2013 ; 39-40$,

18 Cadet-Taïrou A, Lermenier-Jeannet A Gautier S. Profils et pratiques des usagers des CAARUD en 2015. Saint-Denis OFDT 2018. Available at: https://www.ofdt.fr/publications/collections/rapports/rapports-d-etudes/rapports-detudes-ofdt-parus-en-2018/profils-et-pratiques-des-usagers-de-droguesrencontres-dans-les-caarud-en-2015/ (Accessed march 2020)

19 Palle C, Rattanatray, Les centres de soins, d’accompagnement et de prévention en addictologie en 2016. Situation en 2014 et évolutions sur la période 2005-2016, Saint-Denis, OFDT, 2016 Available at : https://www.ofdt.fr/publications/collections/rapports/rapports-d-etudes/rapports-detudes-ofdt-parus-en2018/les-centres-de-soins-daccompagnement-et-de-prevention-en-addictologie-en-2016/ . (Accessed march 2020).

20 Brisacier AC, Collin C. Les traitements de substitution aux opiacés en France : données récentes. OFDT 2014 Tendances 94.Available at: https://en.ofdt.fr/BDD/publications/docs/eftaabua.pdf/ (Accessed march 2020)

21 Chossegros P. Prise en charge de la toxicomanie en France (une histoire). Gastroenterol. Clin. Biol. 2007;31:4544-4550.

22 White RG, Hakim AJ, Salganik MJ, Spiller MW, Johnston LG, Kerr L, Kendall C, Drake A, Wilson D, Orroth K, Egger M, Hladik W. Strengthening the Reporting of Observational Studies in Epidemiology for respondent-driven sampling studies: "STROBE-RDS" statement. Clin Epidemiol. 2015 ;68:1463-71. https://doi.org/10.1016/j.jclinepi.2015.04.002.

23 Centers for Disease Control and Prevention. HIV Surveillance Report, 2017; vol. 29. Available at : http://www.cdc.gov/hiv/library/reports/hivsurveillance.html. (Accessed march 2020)

24 Chossegros P, Di Nino F. Associating conditional cash transfer to universal access to treatment could be the solution to the HCV epidemic among drug users (DUs). Harm Reduction Journal 2018 15:63 
25 National report (2012 data) to the EMCDDA by the Reitox National Focal Point France p117 Available at:

https://www.ofdt.fr/BDD/publications/docs/efnaoftb.pdf (Accessed march 2020))

26 Methods and definitions. European Monitoring Centre for Drugs and Drug Addiction Available at: http://www.emcdda.europa.eu/stats07/PDU/methods (Accessed march 2020)

27 Janssen E, Bastie A. Usage problématique de drogues en France : les prévalences en 2011.: OFDT Focus. 2103. /Consommation et conséquences. Available at : http://www.ofdt.fr/BDD/publications/docs/epfxejt9.pdf (Accessed march 2020)

28 Blackender L, Prestidge. Pan London personalized budgets for rough sleepers. J Integrated Care 2014;22: 23-26.

29 Festinger DS, Dugosh K, Kirby KC, Seymour BL Contingency management for cocaine treatment: cash vs. vouchers. J Subst Abuse Treat 2014;47:168-74.

30 Semaan S1, Santibanez S, Garfein RS, Heckathorn DD, Des Jarlais DC. Ethical and regulatory considerations in HIV prevention studies employing respondent-driven sampling. Int J Drug Policy 2009;20):14-27.

31 Addictions en Grand-Est Consommations de substances psychoactives et offre médicosociale. Partenariat de territoire 2017 Available at :

https://www.ofdt.fr/publications/collections/rapports/portraits-de-territoire/addictions-en-grand-est-consommations-de-substances-psychoactives-et-offremedicosociale/ (Accessed march 2020)

32 Beck F. Jeunes et addiction OFDT 2016 Available at : https://www.ofdt.fr/BDD/publications/docs/JAD2016comp.pdf (Accessed march 2020).

33 Janssen E, Bastie A. Usage problématique de drogues en France : les prévalences en 2011.: OFDT Focus. 2103. /Consommation et conséquences. Available at : http://www.ofdt.fr/BDD/publications/docs/epfxejt9.pdf (Accessed march 2020)

34 Dean D01, Cole V, Bauer DJ. Delineating prototypical patterns of substance use initiations over time. Addiction 2015;110:585-94.

35 DeBeck K, Shannon K, Wood E, Li K, Montaner J, Kerr T. Income generating activities of people who inject drugs. Drug Alcohol Depend 2007 91:50-6.

36 Lopez D, Martineau H, Palle C. Mortalité liée aux drogues illicites - Étude d'une cohorte rétrospective de personnes interpellées pour usage de stupéfiants 2004 OFDT Availbale at : https://www.ofdt.fr/publications/collections/rapports/rapports-d-etudes/rapports-detudes-ofdt-

parus-en-2004/mortalite-liee-aux-drogues-illicites-etude-dune-cohorte-de-personnes-interpellees-pour-usage-de-stupefiants-juillet-2004/ (Accessed march 2020)

37 Brisacier AC. Premiers résultats de l'enquête « cohorte de mortalité d'usagers de stupéfiants ». OFDT 2015. Available at:

https://www.ofdt.fr/BDD/publications/docs/eisxabub.pdf (Accessed march 2020)

38 Walker ER, Pratt LA, Schoenborn CA, Druss BG. Excess mortality among people who report lifetime use of illegal drugs in the United States: A 20-year follow-up of a nationally representative survey. Drug Alcohol Depend 2017;171:31-38.

39 Nambiar D, Weir A, Aspinall EJ, Stoové M, Hutchinson S, Dietze P, Waugh L, Goldberg DJ. Mortality and cause of death in a cohort of people who had ever injected drugs in Glasgow: 1982-2012. Drug Alcohol Depend 2015 Feb 1;147:215-21.

40 Lopez-Quintero C, Roth KB, Eaton WW, Wu LT, Cottler LB, Bruce M, Anthony JC. Mortality among heroin users and users of other internationally regulated drugs: A 27-year follow-up of users in the Epidemiologic Catchment Area Program household samples. Drug Alcohol Depend 2015 Nov 1;156:104-111.

41 Vlahov D1, Wang C, Ompad D, Fuller CM, Caceres W, Ouellet L, Kerndt P, Jarlais DC, Garfein RS; Collaborative Injection Drug User Study. Mortality risk among recent-onset injection drug users in five U.S. cities. Subst Use Misuse 2008;43:413-28.

42 Poorolajal J, Hooshmand E, Mahjub H, Esmailnasab N, Jenabi E. Survival rate of AIDS disease and mortality in HIV-infected patients: a meta-analysis. Public Health. 2016;139:3-12. Available at: https://doi.org/10.1016/j.puhe.2016.05.004. (Accessed march 2020)

43 Roncarati JS, Baggett TP, O'Connell JJ, Hwang SW, Cook EF, Krieger N, Sorensen G. Mortality Among Unsheltered Homeless Adults in Boston, Massachusetts, 2000-2009. JAMA Intern Med 2018;178:1242-1248.

44 Cheung AM1, Hwang SW. Risk of death among homeless women: a cohort study and review of the literature. CMAJ 2004;170:1243-7.

45 Spilka S, Richard JB, Le Nézet O, Janseen E, Brissot A, Philippon A, Shah J, Chyderiotis S, Andler R, Cogordan C. Les niveaux d'usage illicites en France en 2017. OFDT 2019. Available at: https://www.ofdt.fr/BDD/publications/docs/eftxssyb.pdf. (Accessed march 2020)

46 Chiappetta V, García-Rodríguez O, Jin CJ, Secades-Villa R, Blanco C. Predictors of quit attempts and successful quit attempts among individuals with alcohol use disorders in a nationally representative sample. Drug Alcohol Depend 2014;141:138-44.

47 Tworek C, Schauer GL, Wu CC, Malarcher AM, Jackson KJ, Hoffman AC. Youth tobacco cessation: quitting intentions and past-year quit attempts. Am J Prev Med 2014 Suppl 1:S15-27.

48 Allen JA, Gritz ER, Xiao H, Rubenstein R, Kralikova E, Haglund M, Heck J, Niaura R, Vallone DM; WELAS Team. Impact of tobacco control policy on quitting and nicotine dependence among women in five European countries. Tob Control 2014;23:173-7. 
49 Le Nézet O, Spilka S, Laffiteau C, Legleye S, Beck F. Usages de substances psychoactives après 60 ans. Tendances 2009 ;67. . Available at : https://www.ofdt.fr/publications/collections/periodiques/lettre-tendances/consommations-de-substances-psychoactives-apres-60-ans-tendances-67septembre-2009/ (Accessed march 2020)

50 Schifano F, Chiappini S, Corkery JM, Guirguis A. Abuse of Prescription Drugs in the Context of Novel Psychoactive Substances (NPS): A Systematic Review. Brain Sci. 2018;8(4):73. Published 2018 Apr 22. doi:10.3390/brainsci8040073,

51 McColl S, Sellers EM. Research design strategies to evaluate the impact of formulations on abuse liability. Drug Alcohol Depend. 2006;83 Suppl 1:S52S62. doi:10.1016/j.drugalcdep.2006.01.015

52 Hoch E, Niemann D, von Keller R, et al. How effective and safe is medical cannabis as a treatment of mental disorders? A systematic review [published correction appears in Eur Arch Psychiatry Clin Neurosci. 2019 Apr 5;:]. Eur Arch Psychiatry Clin Neurosci. 2019;269(1):87-105.

53 Rucker JJ, Jelen LA, Flynn S, Frowde KD, Young AH. Psychedelics in the treatment of unipolar mood disorders: a systematic review. J Psychopharmacol. 2016;30(12):1220-1229. doi:10.1177/0269881116679368

54 Reiche S, Hermle L, Gutwinski S, Jungaberle H, Gasser P, Majić T. Serotonergic hallucinogens in the treatment of anxiety and depression in patients suffering from a life-threatening disease: A systematic review. Prog Neuropsychopharmacol Biol Psychiatry. 2018;81:1-10.

55 Bahji A, Forsyth A, Groll D, Hawken ER. Efficacy of 3,4-methylenedioxymethamphetamine (MDMA)-assisted psychotherapy for posttraumatic stress disorder: A systematic review and meta-analysis. Prog Neuropsychopharmacol Biol Psychiatry. 2020;96:109735.

56 Whelan A, Johnson MI. Lysergic acid diethylamide and psilocybin for the management of patients with persistent pain: a potential role?. Pain Manag. 2018;8(3):217-229. doi:10.2217/pmt-2017-0068

57 Kennedy MC, Karamouzian M, Kerr T. Public Health and Public Order Outcomes Associated with Supervised Drug Consumption Facilities: a Systematic Review. Curr HIV/AIDS Rep 2017;14:161-183.

58 Tableau de l'économie françoise. INSEE Edition 2017. Chômage. Available at : https://www.insee.fr/fr/statistiques/2569338?sommaire=2587886 (Accessed march 2020)

59 Demoulin J. La gestion du logement social: l'impératif participative. Presses Universitaires de Rennes.2016

60 Kiluk BD, Fitzmaurice GM, Strain EC, Weiss RD What defines a clinically meaningful outcome in the treatment of substance use disorders: reductions in direct consequences of drug use or improvement in overall functioning? Addiction. 2019 Jan;114(1):9-15. doi: 10.1111/add.14289.

\section{Tables}

Table 1: Distribution of observed and weighted prevalence of DUs' characteristics and their homophily 


\begin{tabular}{|c|c|c|c|c|}
\hline & $\begin{array}{l}\text { Observed } \\
\mathrm{Nb}\end{array}$ & $\begin{array}{l}\text { Observed } \\
\%(\mathrm{Cl} 95 \%)\end{array}$ & $\begin{array}{l}\text { Weighted } \\
\%(\mathrm{Cl} 95 \%)\end{array}$ & Homophily \\
\hline \multicolumn{5}{|l|}{ Follow-up: } \\
\hline Never & 79 & $24,1(19,46-28,74)$ & $24 \cdot 6(18-33)$ & $0 \cdot 222$ \\
\hline Continuous & 202 & $61,8(56,53-67,07)$ & $61.9(53 \cdot 1-701)$ & $0 \cdot 156$ \\
\hline Dropout & 45 & $13,8(10,06-17,54)$ & $13 \cdot 5(8 \cdot 5-18 \cdot 5)$ & 0.09 \\
\hline \multicolumn{5}{|l|}{ Sex : } \\
\hline Men & 243 & $74,3(69,56-79,04)$ & $71.1(64-77.7)$ & 0,093 \\
\hline Women & 84 & $25,7(20,96-30,44)$ & $28.9(22.3-36)$ & -0.137 \\
\hline \multicolumn{5}{|l|}{ Age: } \\
\hline$<20$ & 29 & $8 \cdot 9(5,81-11,99)$ & 7,7 (3·7-1.26) & $0 \cdot 198$ \\
\hline $20-29$ & 96 & $29,4(24,46-34,34)$ & $26 \cdot 3(20 \cdot 3-35 \cdot 7)$ & 0.08 \\
\hline $30-39$ & 114 & $34,9(24,46-34,34)$ & $33 \cdot 4(27 \cdot 3-43 \cdot 2)$ & $0 \cdot 114$ \\
\hline $40-49$ & 70 & $21,4(16,95-35,85)$ & $27 \cdot 4(17 \cdot 3-307)$ & 0.073 \\
\hline$>49$ & 18 & $5,5(3,03-797)$ & $5 \cdot 2(2 \cdot 8-7 \cdot 8)$ & 0.054 \\
\hline \multicolumn{5}{|l|}{ Injections: } \\
\hline Yes & 202 & $61,8(56,5-67,07)$ & $60 \cdot 5(53 \cdot-68 \cdot 5)$ & 0,135 \\
\hline No & 125 & $38,2(32,93-43,47)$ & $39 \cdot 5(31.5-47)$ & 0,118 \\
\hline \multicolumn{5}{|c|}{ VHC screening (serology) } \\
\hline \multicolumn{5}{|l|}{ Positive } \\
\hline Negative & 61 & $17(11-24)$ & $16.9(11.2-23.6)$ & 0,159 \\
\hline \multirow[t]{2}{*}{ Unknown } & 206 & $61(53-69)$ & $60.9(53.3-68.7)$ & 0,125 \\
\hline & 60 & $22(15-30)$ & $22.2(14.6-29.9)$ & 0,154 \\
\hline \multicolumn{5}{|c|}{ Precariousness } \\
\hline Low & 160 & $48.9(43.6-54.3)$ & $52.8(40.2-51)$ & 0.103 \\
\hline Average & 101 & $30.9(26.1-36.1)$ & $32.2(26.3-36.2)$ & 0.038 \\
\hline High & 66 & $20.2(16.1-24.9)$ & $15.0(11.6-19.4)$ & 0.255 \\
\hline
\end{tabular}

Homophily refers to the tendency to recruit in the same category with a metric between 1 (recruited and recruits in the same category) and - 1 (recruited and recruits in a different category) Heckathorn's suggests that any value of Homophily $\geq 0.3$ as intermediate homophily and any value $\leq-0.3$ as strong heterophily

Table 2: Precariousness and its categories 


$\begin{array}{lllll}\text { Precariousness } & 0 & 1 & 2 & \text { Total } \\ \text { Score } & & & & \% \text { column }\end{array}$

Health Coverage

\begin{tabular}{lllll}
\hline Low & $123(76.9)$ & $35(21.9)$ & $2(1.3)$ & $160(48.9)$ \\
\hline Average & $5(49.5)$ & $38(37.6)$ & $13(12.9)$ & $101(30.9)$ \\
\hline High & $0(0)$ & $29(43.9)$ & $37(56.1)$ & $66(20.2)$ \\
\hline Total (\% line) & $173(52.9)$ & $102(31.2)$ & $52(15.9)$ & $327(100)$ \\
\hline & Housing & & & \\
\hline Low & $118(73.8)$ & $29(18.1)$ & $138.1)$ & $160(48.9$ \\
\hline Average & $22(21.8)$ & $26(25.7)$ & $53(52.5)$ & $101(30.9)$ \\
\hline High & $0(0)$ & $6(9.1)$ & $60(90.9)$ & $66(20.2)$ \\
\hline Total (\% line) & $140(42.8)$ & $61(18.7)$ & $126(38.5)$ & $327(100)$ \\
\hline & Income & & & \\
\hline Low & $108(68.1)$ & $16(10.0)$ & $35(21.9)$ & $160(48.9)$ \\
\hline Average & $18(17.8)$ & $6(5.9)$ & $77(76.2)$ & $101(30.9)$ \\
\hline High & $0(0)$ & $(0)$ & $66(100)$ & $66(20.2)$ \\
\hline Total (\% line) & $127(38.8)$ & $22(6.7)$ & $178(54.4)$ & $327(100)$ \\
\hline
\end{tabular}

For each table Kendall'tau-b $p<0.0001$

Health coverage: 0 : affiliated to a Social Security scheme with complementary coverage; 1 : affiliated to a Social Security scheme without complementary coverage (including people with CMU universal medical coverage or free health care for people on low incomes); 2 : no Social Security scheme (with or without AME state medical assistance). Housing: 0: long-term (independent or with friends/family); 1 : in an institution or temporarily with friends/family; 2 : homeless or living in a squat. Origin of income : 0: employment income and/or unemployment benefits; 1 : social welfare or funds from third parties; 2 : other funds (illegal or unofficial) and no income.

Tableau 3: Distribution of the precariousness score following age

\begin{tabular}{lllll} 
& $\begin{array}{l}\text { Low } \\
\text { (\% PS) }\end{array}$ & $\begin{array}{l}\text { Average } \\
\text { (\% PS) }\end{array}$ & $\begin{array}{l}\text { High } \\
\text { (\% PS) }\end{array}$ & $\begin{array}{l}\text { Total } \\
\text { (\% total) }\end{array}$ \\
\hline$<$ 20 years & 5 & 13 & 11 & 29 \\
& $(17.2)$ & $(44.8)$ & $(37.9)$ & $(8,9)$ \\
\hline 20-29 years & 44 & 29 & 23 & 96 \\
\hline 30-39 years & $(45.8)$ & $(30.2)$ & $(24.0)$ & $(29,4)$ \\
& 60 & 33 & 21 & 114 \\
\hline 40-49 years & $(52.6)$ & $(29.9)$ & $(18.4)$ & $(34,9)$ \\
& 37 & 23 & 10 & 70 \\
\hline 49 years & $(52.8)$ & $(32.9)$ & $(14.3)$ & $(21,4)$ \\
& 14 & 3 & 1 & 18 \\
\hline Total & $(77.8)$ & $(16.7)$ & $(5.8)$ & $(5,5)$ \\
(\% precariousness) & $(48,9)$ & $(30,9)$ & $(20,2)$ & $(100)$
\end{tabular}

Kendall tau- $b<0,0001$ 


\begin{tabular}{|c|c|c|c|c|c|}
\hline & Age of initiation & $\begin{array}{l}\text { Life } \\
\text { (\%) }\end{array}$ & $\begin{array}{l}\text { Life IV } \\
\text { (\%) }\end{array}$ & $\begin{array}{l}30 \text { days } \\
(\%)\end{array}$ & $\begin{array}{l}30 \text { days IV } \\
(\%)\end{array}$ \\
\hline \multirow[t]{2}{*}{ Cannabis } & 14,1 & 97,6 & 0 & 80,7 & 0 \\
\hline & $15.6 / 14.8 / 14^{\star}$ & & & & \\
\hline \multirow[t]{2}{*}{ Heroïn } & 17,2 & 92,4 & 52 & 67,2 & 19,3 \\
\hline & $21.5 / 19,4 / 18.3^{\star}$ & & & & \\
\hline Cocaïne & 17,8 & 92,7 & 37,6 & 48,6 & 14,4 \\
\hline Ecstasy & 18,3 & 79,9 & 9,5 & 21,7 & 0 \\
\hline \multirow[t]{2}{*}{ Alcohol } & 14,7 & 79,2 & 0 & 60,6 & 0 \\
\hline & $17.4 / 16,9 / 14.8^{*}$ & $73.1 / 81,2 / 90.9 * \star$ & & $50 / 69,3 / 72.7^{\star \star}$ & \\
\hline \multirow[t]{2}{*}{ Diverted OST } & 21,4 & 73,1 & 25,1 & 47,4 & 11,3 \\
\hline & $25,5 / 23,75 / 20,5^{\star}$ & & & & \\
\hline Amphetamine & 19,7 & 72,2 & 18,3 & 26,4 & 4,9 \\
\hline LSD & 19,2 & 68,2 & 4,6 & 15,9 & 0 \\
\hline Hallucinogen & 19,1 & 69,7 & 1 & 12,2 & 0 \\
\hline Benzodiazepine & 20,1 & 56 & 4,3 & 35 & 0,9 \\
\hline Ketamine & 24,6 & 47,4 & 12,2 & 9,8 & 1,8 \\
\hline Codeine & 18,4 & 38,4 & 2,4 & 14,7 & 0,6 \\
\hline
\end{tabular}

Life: \% Lifelong use

Life IV: \% lifelong injections

30 days: \% use during the last 30 days*

30 days IV: \% having injected during the last 30 days

OST: opioid substitution therapy

.../.../... : Low/Average/High precariousness score when different for precariousness score

* Kendall tau-b $p=0,001$, ** Kendall tau-b $p<0,0001$

Table 5 : Sources of information 


\begin{tabular}{llll} 
Sources of information & Generalist & Health & Drugs \\
& $\%$ & $\%$ & $\%$ \\
\hline None & 4 & 11.9 & 9.8 \\
\hline Friends & 67.9 & 37 & 60.2 \\
\hline Family & & 14.1 & 8.9 \\
\hline Television & 65.4 & 26.3 & 32.1 \\
\hline Press (free) & $67.4 / 56 / 31.4^{*}$ & & \\
\hline Press (paid for) & 44 & 12.8 & 15.3 \\
\hline Internet & 14.7 & 2,4 & 5.8 \\
\hline Social Networks & 52.8 & 29.4 & 41,9 \\
\hline GP & $66.9 / 45.5 / 30.3^{*}$ & $39.4 / 21.8 / 16.7^{*}$ & $53.8 / 31.7 / 28.8^{*}$ \\
\hline CSAPA, CAARUD & & 7.6 & 10.1 \\
\hline Pharmacy & & 55 & 32.1 \\
\hline Stand & & $65 / 55.4 / 30.3^{*}$ & $43.1 / 29.7 / 9.1^{*}$ \\
\hline Booklet & & 27.5 & 25.1 \\
\hline & & 11.3 & 8.3 \\
\hline & & 15.3 & 23.9 \\
\hline & & 26.1 & \\
\hline & & & 26 \\
\hline
\end{tabular}

* : Kendall tau-b $\mathrm{p}<0.0001$

.../...... : Low/Average/High precariousness score when significantly different

Table 6: Binary logistic regression (forward stepwise selection) for precariousness score (Low versus High precariousness scores)

\begin{tabular}{lllllll} 
& B & Wald & Sig & Odds ratio & \multicolumn{2}{c}{$95 \%$ Cl of OR } \\
\cline { 6 - 7 } & & & & & Lower & Upper \\
\hline Source GP health & 1.517 & 5.453 & 0.020 & 4.558 & 1.276 & 16.285 \\
\hline Source Internet drugs & -1.638 & 5.919 & 0.015 & 0.194 & 0.052 & 0.727 \\
\hline Contact parents & -2.430 & 18.302 & 0.0001 & 0.088 & 0.029 & 0.268 \\
\hline Contact drug dealer & 0.194 & 8.218 & 0.004 & 1.1214 & 1.063 & 1.385 \\
\hline Age & -0.004 & 8.611 & 003 & 0.910 & 0.854 & 0.869 \\
\hline Follow-up GP & -1.932 & 7.943 & 0.005 & 0.145 & 0.038 & 0.555 \\
\hline Alcohol (30 days) & -1.689 & 6.341 & 0.012 & 0.185 & 0.050 & 0.688 \\
\hline Finding housing & -1.810 & 9.377 & 0.002 & 0.164 & 0.051 & 0.521 \\
\hline Social rights & -2.933 & 11.703 & 0.001 & 0.053 & 0.010 & 0.285 \\
\hline Education & -1234 & 10.666 & 0.001 & 0.291 & 0.139 & 0.611 \\
\hline Constant & 10.429 & 25.033 & 0.0001 & 33826.670 & & \\
\hline
\end{tabular}

Hosmer and Lemeshow test : 2.554 ; CC : LPS: $94.4 \%$, HPS: $84.8 \%$ Total: $91.6 \%$

CC: correctly classified

Figures 


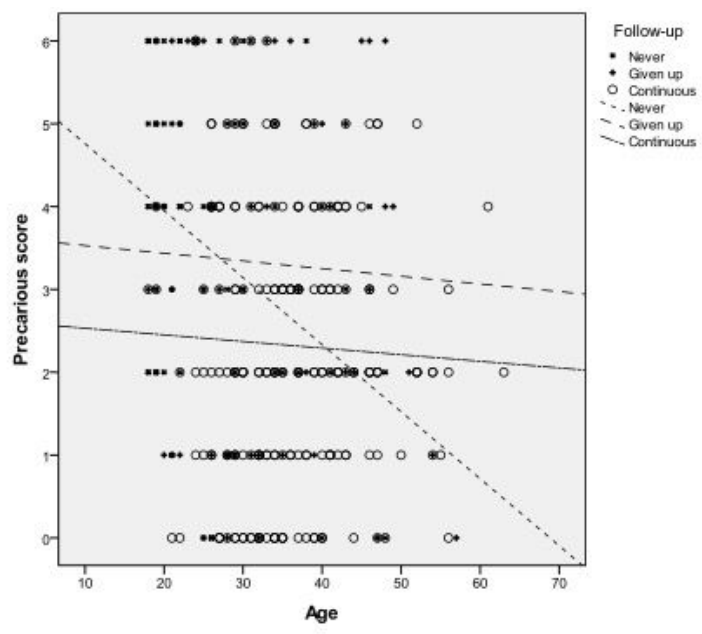

\section{Figure 1}

Distribution of the precarious score following age and use of health services for DUs. Lines are linearly fitted to each subgroup. 